\title{
Assessment of investment decisions in bulk shipping through fuzzy real options analysis
}

\author{
Xiayan Zhang ${ }^{1} \cdot$ Jingbo Yin ${ }^{1}$
}

Accepted: 13 September 2021 / Published online: 4 October 2021

(c) The Author(s), under exclusive licence to Springer Nature Limited 2021

\begin{abstract}
The global shipping market has been depressed and turbulent since 2008. Shipping companies have had to be more cautious with their investments, so as to buck the trend and get through this difficult period. Traditional net present value methods cannot help enterprises make effective investment decisions. Therefore, we employ real options theory-including expansion options, contraction options, deferral options, and abandonment options - to simulate various types of operational adjustment strategies used by investors in the process of ship investment and operations. Triangular fuzzy numbers and the generalized autoregressive conditional heteroscedasticity model are also introduced to describe the uncertainty and volatility of the shipping market. Subsequently, a fuzzy real options binomial tree pricing model is developed to assess the project value of ship investments. Based on the calculations and analysis of an actual ship investment case, the fuzzy real options method is shown to be more suitable for ship investment analysis, fitting more closely the actual market and operating situation.
\end{abstract}

Keywords Ship investment · Real options · Fuzzy theory · Binomial tree model · Deferral option · Expansion option

\section{Introduction}

The 2008 financial crisis had a sizeable impact on world trade, and the economies of both developing and developed countries experienced significant fluctuations. As an important supporting service to world trade, the shipping industry was also significantly affected: freight rates fell sharply, and international shipping entered a period of cyclical variation, with a lengthy trough period. For example, the Baltic Dry

Jingbo Yin

jingboyin@sjtu.edu.cn

1 State Key Laboratory of Ocean Engineering, Department of International Shipping, School of Naval Architecture, Ocean and Civil Engineering, Shanghai Jiao Tong University, Shanghai, China 


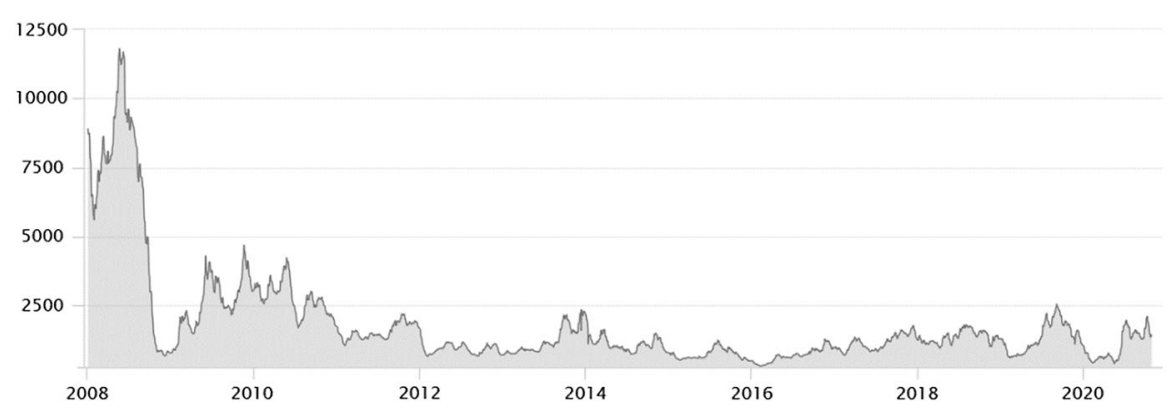

Fig. 1 Baltic Dry Index from June 2008 to October 2020

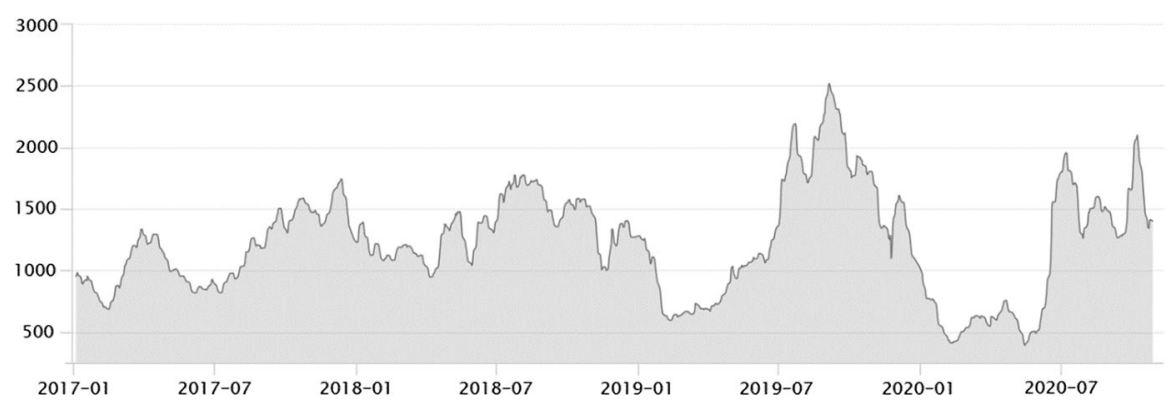

Fig. 2 Baltic Dry Index from January 2017 to October 2020

Index (BDI), an authoritative measure of international shipping activity (prices), has been fairly low since December 2008 (Fig. 1). Although the industry entered a recovery period in 2017, the BDI did not return to pre-crisis levels (Fig. 2). It has also remained unstable, even over short periods of time. Such short-term changes are often very pronounced, reflecting the turmoil in shipping markets.

Shipping companies invest in ships to augment capacity, but also for speculative purposes (asset play), for ships are highly tradeable assets. In a narrower sense, ship investment concerns the ordering of new ships, the acquisition of secondhand ones or the leasing of tonnage. Ships are complex, capital-intensive investments, with long payback periods and subject to a volatile environment. Market risk is therefore high, accentuated by technological and policy changes. As such, opportunities and challenges co-exist, and the timing of investment is the paramount consideration, accompanied, of course, by rigorous investment analysis.

In most cases, shipping companies base their decisions on traditional discounted cash flow methods, often accompanied by market risk simulation. The real options approach adopted here instead considers uncertainty, often neglected in NPV analyses, as a positive factor, accounting for the value of the investment given uncertainties such as price fluctuations.

We use fuzzy real options analysis (fuzzy ROA) to value ship investments. Expansion options, contraction options, deferral options and abandonment options are used to simulate the various operational decision behaviours in the process of 
ship investment and operations. Triangular fuzzy numbers are introduced to further simulate the uncertainty of the underlying asset volatility. Shipping market volatility is calculated using the generalized autoregressive conditional heteroscedasticity (GARCH) model, estimated on historical data. A fuzzy real options model is thus established to evaluate ship investment values of relevant decisions.

The remainder of the paper is organized as follows. Section 2 introduces research related to investment decisions, real options and fuzzy options. In Sect. 3, the ROA of shipping investment and volatility is first described, and then the fuzzy real options pricing model is introduced. The application of the model to a specific case study is presented in Sect. 4. Section 5 contains a deeper discussion, and Sect. 6 draws the final conclusions.

\section{Literature review}

Ship investment decisions are typical of project investment decision problems. In investment analysis, traditional discounted cash flow (DCF) methods are typically used. Bendall (1979) and Evans (1984) were the first to apply this approach to ship investments, and since then it has become the most commonly used method in this area. However, because traditional project decision-making ignores the value of risk adjustments made by the manager, new methods have emerged to address this limitation; ROA is one of them. The concept of real options was first proposed by Myers (1977), who pointed out that profit generated by cash flow in an investment plan comes not only from the actual use of the assets currently owned but also from the value of a choice of opportunities in future investment. Slade (2001) defined real options in mining investments, where the value of management flexibility was assessed using data on ore prices, costs, grades, reserves, ore mining and metal production. Bendall and Stent (2007) used the real options method in an analysis of ship investments under uncertainty and found that ROA can be used to estimate project value and option value, providing a scientific theoretical basis for ship investment decisions, together with verifying the effectiveness of real options. Bendall and Stent $(2003,2007)$ also extended their study of real options via a sensitivity analysis, demonstrating that the value of real options is highly correlated with the volatility of risk-return streams. They applied the results of their real options and NPV analyses to a case study. Dikos (2008) used ROA for research into the tanker market and oil transportation, proposing a balanced model to explain the overall investment behaviour of the tanker shipbuilding industry. Acciaro (2014) used a real options model to analyse whether shipowners should invest in retrofitting existing vessels with liquefied natural gas (LNG), in order to comply with Emission Control Areas rules in 2015. Kyriakou et al. (2018) used ROA to make predictions in the dry bulk shipping market, and built a model to evaluate actual assets and determine the best investment timing. Yin et al. (2018) used the compound option of abandonment and deferral options to evaluate the behaviour of stopping operations and terminating investments in a market downturn. By applying ROA, Yin's study of ship investment decisions was able to take into account the cyclical changes in the shipping market and the value of the real options. 
Previous research on project decision-making using ROA has therefore been based on deterministic analyses. However, given the market uncertainty, describing the magnitude of changes in the underlying asset directly in terms of fixed values does not fully reflect the reality of project investment. Fuzzy theory, thus, provides a new research direction in option pricing. For financial options, many researchers have used it to improve the classic option pricing model. Yoshida (2003) provided a new way to price European-style call and put options by constructing a fuzzy objective function, and discussed the meaning and properties of rational expected prices in the context of a numerical example. Muzzioli and Reynaerts (2007) modelled the uncertainty of the key parameters of the underlying asset by introducing triangular fuzzy numbers, and obtained the distribution of the risk-neutral probability, thus establishing an American-style options pricing model based on fuzzy theory. Chrysafis and Papadopoulos (2007) combined fuzzy theory with the Black-Scholes (B-S) pricing model to estimate the relevant parameters using the fuzzy number method, which opened up new possibilities for fuzzy options pricing.

Some scholars have explored the application of real options pricing theory with fuzzy properties. Carlsson and Fullér (2003) used trapezoidal fuzzy numbers to estimate the present value of expected cash flows and expected opportunity cost. Hye and Eunnyeong (2009) included new information in value evaluation results by applying a fuzzy risk analysis to the real options model in the context of a gas hydrate development project. Allenotor and Thulasiram (2011) treated the pricing of grid computing cycles as a real options pricing problem, modelled the spot price of grid resources using a discrete-time approach, and used fuzzy logic to solve the uncertainty constraints on the provision of quality of service. Arasteh and Aliahmadi (2013) designed a new dynamic model of real-world systems based on the concepts of system dynamics (SD) and a fuzzy logic approach. This method was explained with an example from aviation, demonstrating that the fuzzy-SD synthesis model can help investors to choose an investment option. However, there are still relatively few studies that have combined fuzzy theory with real options applications in the shipping industry.

\section{Methodology}

\subsection{Real options analysis}

In the financial sector, an option is the right of the holder to buy or sell a certain amount of financial assets (such as stocks, bonds, or currencies) at an agreed price within a specified time. Options are distinguished as American-style and Europeanstyle, depending on whether they can be exercised before their expiry date. The buyer of an American-style option can execute the contract on the expiration date or any trading day before this, whereas a European-style option can be exercised at expiration only. A real option is the expansion and application of the financial option concept in the area of physical project investment. Thus, a real option can be regarded as the right of a company to buy or sell physical assets or execute investment plans, and this right can be evaluated similarly to a financial option. In ship 
investment, holders of real options have the flexibility to shift their investment behaviour in response to the volatility of the shipping market and their prognosis of the ship investment environment.

Ship investment decisions take place amongst constantly changing market conditions, new policies and many other complex external factors. The investor will therefore adjust its investment behaviour according to external forces in order to obtain the maximum benefit. The main risk in the operating period is the volatility of the shipping market. Specifically, when the market is good, a company will strive to expand the scale of its operations by adding ships or increasing the ship utilization rate; this is defined here as an expansion option. In contrast, if the market is poor, the shipping company will reduce the scale of its operations by carrying less cargo with the same ships, through slow-steaming, or laying up part of its fleet to reduce operating costs; this is the contraction option. An alternative, the deferral option, is the shipping company's choice to lay up the ships during a market downturn and reactivate them when the market recovers to a certain level. However, in a worst-case situation, the shipping company would incur huge losses by continuing to hold its ships, and would therefore sell or scrap all of its ships and exit shipping all together. This would entail the shipping company giving up all its rights, as mentioned above, and is defined as the abandonment option.

Table 1 provides the relevant notations for the ship investment real options model. The model is presented below.

\subsection{Volatility and fuzzy rising and falling factors}

In ship investment, volatility refers to fluctuations in the value of the project, which is an important discriminant variable for the uncertainty and risk of the shipping market. In financial options research, volatility is usually the degree of fluctuation of the underlying price, while in real options research, it is necessary to find corresponding indicators that can reflect the fluctuation in the value of the investment. Specifically, in a ship investment project, a freight rate index, a dynamic relative number reflecting the trend and extent of freight rate changes in different periods, is used to express volatility. Many such indices exist in shipping, such as the BDI and the China Containerized Freight Index (CCFI). The index used in the calculation of volatility is selected according to the specific vessel type and intended trades.

For the estimation of volatility, common methods include the cash flow logarithmic income method, the logarithmic present value method, the Monte Carlo simulation method, the historical data method, the autoregressive conditional heteroscedasticity $(\mathrm{ARCH})$ model prediction method and the GARCH model prediction method. Given the volatility of the shipping market and its inherently cyclical financial characteristics, the ARCH and GARCH models are the more commonly used. The GARCH model is a generalized ARCH model, proposed by Bollerslev (1986), that expands and refines the ARCH model. Kavussanos $(1996,1997)$ argued that the GARCH model is more appropriate than the ARCH model for defining freight rates and freight rate volatility. A generalized autoregressive conditional heteroscedasticity time series $\operatorname{GARCH}(p, q)$ of order $p$ and $q$ satisfies the following conditions: 
Table 1 The notation and definitions

\begin{tabular}{|c|c|c|}
\hline Notation & Definition & Unit \\
\hline$\sigma$ & The volatility & N/A \\
\hline$p$ & The lag order of the GARCH term & N/A \\
\hline$q$ & The lag order of the ARCH term & N/A \\
\hline$u$ & The rising factor & N/A \\
\hline$d$ & The falling factor & N/A \\
\hline$\tilde{u}$ & The fuzzy rising factor & N/A \\
\hline$\tilde{d}$ & The fuzzy falling factor & N/A \\
\hline$\lambda$ & The risk preference parameter & N/A \\
\hline$\rho$ & The sensitivity factor & N/A \\
\hline$r$ & The risk-free interest rate & N/A \\
\hline$P$ & The rising probability of the option value & N/A \\
\hline$S_{0}$ & The initial underlying asset value & Million dollars \\
\hline$\tilde{S_{i, j}}$ & The fuzzy underlying asset value in period $i$, state $j$ & Million dollars \\
\hline$S_{i, j}$ & The most likely value of $\tilde{S_{i, j}}$ & Million dollars \\
\hline$\tilde{C}_{i, j}$ & The fuzzy option value during period $i$ for situation $j$ & Million dollars \\
\hline$C_{i, j}$ & The most likely value of $\tilde{C}_{i, j}$ & Million dollars \\
\hline $\mathrm{AOC}$ & The average operating cost & Million dollars \\
\hline $\mathrm{FC}$ & The fixed cost of ships & Million dollars \\
\hline$Q$ & The ships' capacity under the operational state & Tons/days \\
\hline$\alpha$ & Expansion factor & N/A \\
\hline$\beta$ & Contraction factor & N/A \\
\hline$F_{\mathrm{e}}$ & The ships' expansion cost & Million dollars \\
\hline$F_{\mathrm{c}}$ & The ships' contraction value & Million dollars \\
\hline$S_{\mathrm{e}}$ & The expansion underlying asset value & Million dollars \\
\hline$S_{\mathrm{c}}$ & The contraction underlying asset value & Milliondollars \\
\hline$S_{\mathrm{s}}$ & The underlying asset value of stopping node & Million dollars \\
\hline $\mathrm{S}_{\mathrm{r}}$ & The underlying asset value of restarting node & Million dollars \\
\hline $\mathrm{SC}$ & The stopping cost & Million dollars \\
\hline $\mathrm{RC}$ & The restarting cost & Million dollars \\
\hline$T_{\mathrm{A}(i, j)}$ & The abandonment trigger during period $i$ for situation $j$ & Million dollars \\
\hline$A_{i j}$ & The abandonment option value & Million dollars \\
\hline $\mathrm{ABC}$ & The ships' abandonment cost & Million dollars \\
\hline$T_{i}$ & The residual value of the vessel in period $i$ & Million dollars \\
\hline$R_{i j}$ & The operation revenue if do not execute abandonment option & Million dollars \\
\hline$n$ & The investment horizon & N/A \\
\hline$\widetilde{\mathrm{CF}}_{i}$ & The fuzzy total compound option value during period i & Million dollars \\
\hline$\widetilde{\mathrm{PV}}$ & The fuzzy total present value of the ship investment project & Million dollars \\
\hline PV & The total present value of the shipping investment & Million dollars \\
\hline$T_{\mathrm{O}}$ & The capital investment costs of the vessel & Million dollars \\
\hline
\end{tabular}




$$
\begin{gathered}
\operatorname{GARCH}(p, q)=\sigma_{t} \varepsilon_{t}, \\
\sigma_{t}^{2}=a_{0}+\sum_{i=1}^{p} b_{i} X_{t-i}^{2}+\sum_{j=1}^{q} a_{j} \sigma_{t-j}^{2} .
\end{gathered}
$$

If the sequence satisfies a strictly smooth process with unique finite second-order moments,

$$
\sum_{i=1}^{p} b_{i}+\sum_{j=1}^{q} a_{j}<1
$$

then the series is smooth, and the long-term volatility will be stable:

$$
\sigma^{2}=\frac{a_{0}}{1-\sum_{i=1}^{p} b_{i}-\sum_{j=1}^{q} a_{j}} .
$$

The rising and falling factors in the ROA method can be calculated from the $\sigma$, calculated by the GARCH model:

$$
u=\mathrm{e}^{\sigma} ; \quad d=\frac{1}{u}=\mathrm{e}^{-\sigma} .
$$

The rising and falling factors are the key parameters in a real options pricing model; they reflect the market trend and determine the specific freight rates, under different market conditions and points in time, which directly affect the real options value of the project. In the traditional real options pricing model, the rising and falling factors are calculated from the volatility and then applied directly to the options pricing. However, the actual movement of the shipping market cannot be predicted with precision, and the expansion of rising and falling factors, from specific values to an interval, can improve the application of real options to the pricing of the investment. This improvement is achieved by introducing triangular fuzzy numbers to the fuzzification of the rising and falling factors.

Zadeh (1965) - an American cybernetics expert - introduced the important concept of fuzzy sets to portray fuzzy concepts and fuzzy phenomena quantitatively. We can define $U$ as domain of discourse and $\tilde{A}$ as a subset on $U$. For any element $x \in U$, the function

$$
u_{\tilde{A}}: U \rightarrow[0,1]
$$

pecifies a value $u_{\tilde{A}}(x) \in[0,1]$ corresponding to $x$. The value of $u_{\tilde{A}}(x)$ at element $x$ reflects the degree to which element $x$ belongs to $\tilde{A}$. The set $\tilde{A}$ is called a fuzzy subset, and $u_{\tilde{A}}(x)$ is called the membership function of $\tilde{A}$. The triangular fuzzy number can be represented by a ternary variable $\langle a, b, c\rangle$, where $a$ indicates the most pessimistic value, $b$ is the most likely value, and $c$ is the most optimistic value (a fuller discussion of fuzzy numbers is given in the "Appendix"). The expected value of a triangular fuzzy number is given by $E(\tilde{A})=[(1-\lambda) a+b+\lambda c] / 2$. The choice of $\lambda$ value depends on the risk attitude of the decision-maker. When $1>\lambda>0.5$, the 
decision-maker is optimistic; when $\lambda=0.5$, the decision-maker is neutral; and when $0.5>\lambda>0$, the decision-maker is pessimistic. The fuzzification of the rising and falling factors is achieved by introducing a sensitivity factor $\rho \in[0,1]$. The triangular fuzzy forms of the rising factor and the falling factor are defined as follows:

$$
\begin{gathered}
\tilde{u}=\left\langle\mathrm{e}^{(1-\rho) \sigma}, \mathrm{e}^{\sigma}, \mathrm{e}^{(1+\rho) \sigma}\right\rangle, \\
\tilde{d}=\left\langle\mathrm{e}^{-(1+\rho) \sigma}, \mathrm{e}^{-\sigma}, \mathrm{e}^{-(1-\rho) \sigma}\right\rangle .
\end{gathered}
$$

\subsection{Fuzzy options pricing model}

The ROA method converts a ship investment case into a real options model for computational analysis. This is a process of mathematical abstraction and modelling based on the following four assumptions: (1) the shipping market is a perfectly competitive market ${ }^{1}$; (2) the risk-free interest rate, $r$, is of a fixed value; (3) the volatility of the underlying asset does not change; and (4) the investor is risk-neutral.

The key to the ROA method is to build a pricing model by which to price the ship investment. Black and Scholes (1973) defined the initial options pricing formula and proposed the B-S options pricing model. Another major options pricing method is the binomial tree approach, developed by Cox et al. (1979) as a simple way to price discrete-time options. The basic idea of the Cox model is to divide the real option into several time intervals during the validity period. In each time interval, the price of the underlying asset has a probability of moving up or down to two new values of $P$ and $1-P$, respectively. The backward calculation obtains a binomial tree for the underlying asset. At each time node, the decision-maker can choose to execute the option or not, using the binomial tree backpropagation rule to obtain the value of the real option. Given the flexibility of ship investment operations and the simplicity of the computational model, the binomial tree model, combined with triangular fuzzy numbers, is used here in our fuzzy options pricing model.

The first step in establishing a real options model for ship investment projects is to determine the type of real option (expansion, contraction, deferral or abandonment). The next step is to determine the option validity period and divide that period into multiple time intervals according to operational needs; ship investment real options are usually divided into years.

A fuzzy underlying asset binomial tree is then created. The selection of the underlying asset is determined by the vessel type, which is also the revenue form of the ships. In bulk shipping spot fixtures, the freight rate is selected as the underlying asset; in time-charters, instead, the charter hire is selected. The current freight rate or charter hire in the decision analysis period is used as the starting node of the underlying asset binary tree, while the fuzzy rising factor and fuzzy falling factor are used to calculate the fuzzy underlying asset value in period $i$, state $j$, according to the following equation:

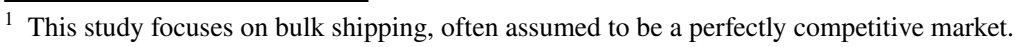


Fig. 3 Fuzzy binary tree

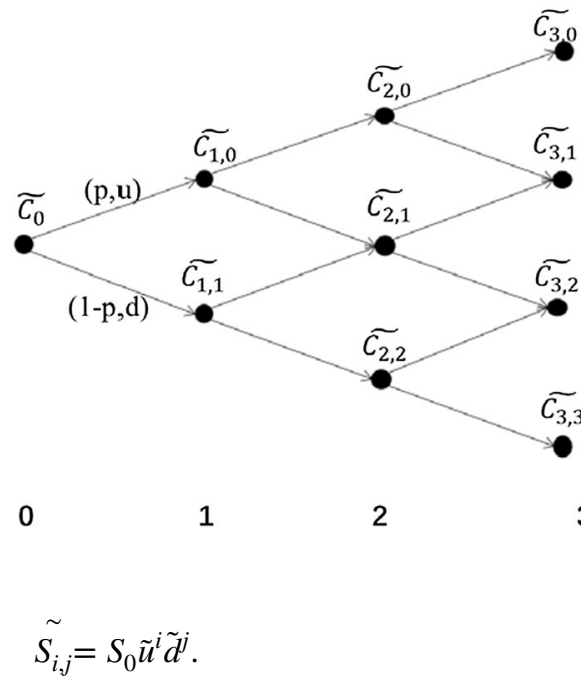

As detailed in Sect. 3.2, $u$ and $d$ are the volatility ranges of rising and falling, and $P$ and $1-P$ are the probabilities of rising and falling. According to the assumptions of the binomial tree changing factor, the probability $P$ can be calculated by $\frac{\mathrm{e}^{r T}-d}{u-d}$. Based on the fuzzy underlying asset binomial tree, the project cash flows $\left[\left(\tilde{S_{i, j}}-\mathrm{AOC}\right) * Q-\mathrm{FC}\right]$ at each node can be calculated, and the decision as to whether to execute each type of real option at the corresponding node is considered to obtain the fuzzy option value binomial tree (Fig. 3).

Where AOC is the average operating cost, $Q$ is the ships' capacity in operations, and FC is the fixed cost of ships.

The real option for ship operations is made up of the four types of options described above. As they are all American-style options, the execution of each option needs to be judged at each node before the maturity date. One assumption of real options in ship investment is that the judgement of the option execution is assumed to be influenced only by the shipping market, because that is the most significant source of risk in vessel operations. In the fuzzy binomial tree, because the changing factor is fuzzified, the underlying asset and the option value obtained from the calculation are also fuzzy numbers. To fit the actual situation and simplify the calculation, the most likely value of each fuzzy node $S_{i, j}$ is selected for the relevant calculation when judging the option execution.

Further simplifications can be made by considering the specific characteristics of the four options. During the ship construction period, the decision-maker will generally adopt a strategy of expanding or contracting the scale of the ship operations according to the market conditions at the end of a specified period (for example, after 3 years of operating the ships). At the specified time, if market conditions are good, the expansion option is mainly under consideration; conversely, if market conditions are poor, the contraction option is under consideration. For the expansion option, the decision-maker will consider expanding ship operations by adding ships or increasing the ship utilization rate to obtain higher 
operating income with an expansion factor $\alpha(\alpha>1)$ and an expansion cost $F_{\mathrm{e}}$. The expansion underlying asset value is calculated as follows:

$$
S_{\mathrm{e}}=\mathrm{AOC}+\frac{\mathrm{FC}}{Q}+\frac{F_{\mathrm{e}}}{\alpha Q} .
$$

For the contraction option, the shipping company will scale down its ship operations to reduce operating costs with a contraction factor $\beta(\beta<1)$ and a contraction value of $F_{\mathrm{c}}$. The contraction underlying asset value is calculated as follows:

$$
S_{\mathrm{c}}=\mathrm{AOC}+\frac{\mathrm{FC}}{Q}-\frac{F_{\mathrm{c}}}{\beta Q} .
$$

When the most likely underlying asset value $S_{i, j}$ is higher than the expansion underlying asset value $S_{\mathrm{e}}$, the shipping company will execute the expansion and the option value will expand to $\alpha$ times its original value. When $S_{i, j}$ is lower than $S_{\mathrm{c}}$, the shipping company will execute the contraction option and the option value will shrink to the original $\beta$ times.

The deferral and abandonment options are considered in advance in the case of poor market conditions, and focus mainly on the lower half of the binomial tree. Judging the execution of the deferral option at each node entails finding the stopping node and the restarting node of the binary tree. The underlying asset value of the stopping and restarting nodes can be defined as follows:

$$
\left\{\begin{array}{l}
S_{\mathrm{s}}=\mathrm{AOC}-\mathrm{SC} / Q, \\
S_{\mathrm{r}}=\mathrm{AOC}+\mathrm{RC} / Q .
\end{array}\right.
$$

When the underlying asset value of the node is lower than the stopping asset, the decision-maker will choose to suspend ship operations; when the underlying asset value of the node is higher than the starting asset, the decision-maker will choose to restart ship operations. The fuzzy option value of the deferral option can be calculated using the following equation:

$$
\tilde{C_{i, j}}= \begin{cases}\left(\tilde{S_{i, j}}-\mathrm{AOC}\right) * Q-\mathrm{FC}, & S_{i, j}>S_{\mathrm{r}}, \\ \text { depends on } S_{i-1, j}, & S_{\mathrm{s}}<S_{i, j}<S_{\mathrm{r}}, \\ -\mathrm{SC}-\mathrm{FC}, & S_{i j}<S_{\mathrm{s}} .\end{cases}
$$

Finally, consider the execution of the abandonment option. As this option means that the shipping company will sell the ships and exit the shipping market, the node that executes the abandonment option will directly affect the option value of all subsequent nodes. Therefore, judgement of the abandonment node is not a direct comparison of the underlying asset value of a single node; instead, all the income of the ship investment project after the expiration date in the state of each node must be considered. The trigger of the abandonment option is defined as follows: 


$$
T_{\mathrm{A}(i, j)}=\sum_{u=i+1}^{n}\left[\frac{1}{\mathrm{e}^{r(u-i)}} * \sum_{v=j}^{u} \frac{u !}{v !(u-v) !} P^{u-v}(1-P)^{v} C_{u, v}\right]+\mathrm{ABC} .
$$

If $T_{\mathrm{A}(i, j)}<0$, there will be no more revenue after this node if the shipping investors continue to hold the ship and conduct business activities; the abandonment option should be executed at that node. The option value of the abandonment option and all the subsequent nodes are adjusted to zero. For all nodes in the option value binary tree, the following formula can be used to adjust the abandonment option value:

$$
A_{i j}= \begin{cases}T_{i}-R_{i j}-\frac{T_{n}}{\mathrm{e}^{\mathrm{r}(n-i)}}-A B C, & T_{\mathrm{A}(i, j)}<0, \\ 0, & T_{A(i, j)}>0 .\end{cases}
$$

The fuzzy total compound option value $\widetilde{\mathrm{CF}}_{i}$ for period $i$ can be calculated as follows:

$$
\widetilde{\mathrm{CF}}_{i}=\mathrm{e}^{-r i} * \sum_{j=0}^{i} \frac{i !}{j !(i-j) !} P^{i-j}(1-P)^{j}{\widetilde{C_{i, j}}}
$$

Then the fuzzy total value of the ship investment project can be calculated as shown:

$$
\widetilde{\mathrm{PV}}=-T_{\mathrm{O}}+\sum_{i=1}^{n} \widetilde{\mathrm{CF}}_{i}+\frac{T_{n}}{\mathrm{e}^{r n}}
$$

The PV obtained here is the fuzzy total present value of the ship investment project, combined with the shipping company's risk attitude to the actual situation of the market, policy, ship operation and other factors. The total present value of the ship investment project PV can be obtained by calculating the expected value of the fuzzy number.

\section{Case study}

In this study, a real ship investment case is developed to analyse the application of the fuzzy options pricing model presented above. In 2017, COSCO Marine Energy Transportation Co. Ltd. raised $\$ 5.4$ billion to purchase 16 new tankers, including four 320,000-ton very large crude carriers (VLCCs), which is here our research focus. This paper argues that the shipowner should operate the four VLCCs as a whole, with an initial planned operation period of 5 years. At the time, the order price of each VLCC was $\$ 56.5$ million, and the 1-year charter rate was $\$ 27,087$ per day. The risk-free interest rate was $3 \%$, and the annual depreciation rate was assumed by COSCO to be $5 \%$. 
Table 2 Augmented Dickey-Fuller (ADF) unit root test

\begin{tabular}{|c|c|c|c|c|}
\hline & & \multicolumn{2}{|l|}{$t$-Statistic } & Probability* \\
\hline \multicolumn{2}{|c|}{ Augmented Dickey-Fuller test statistic } & -18.90563 & & 0.0000 \\
\hline \multicolumn{5}{|l|}{ Test critical values: } \\
\hline \multicolumn{2}{|l|}{$1 \%$ level } & \multicolumn{3}{|l|}{-3.433897} \\
\hline \multicolumn{2}{|l|}{$5 \%$ level } & \multicolumn{3}{|l|}{-2.862993} \\
\hline \multicolumn{2}{|l|}{$10 \%$ level } & \multicolumn{3}{|l|}{-2.567591} \\
\hline Variable & Coefficient & SE & $t$-Statistic & Probability \\
\hline DLNRBDTI $(-1)$ & -0.452092 & 0.023913 & -18.90563 & 0.0000 \\
\hline$D(\operatorname{DLNRBDTI}(-1))$ & -0.099918 & 0.023852 & -4.189045 & 0.0000 \\
\hline$C$ & $-3.97 \times 10^{-5}$ & 0.000350 & -0.113491 & 0.9097 \\
\hline
\end{tabular}

*MacKinnon (1996) one-sided $P$-values

\subsection{Volatility and changing factor calculations}

Because the case under analysis is one of dirty tanker shipping, the Baltic Dirty Tanker Index (BDTI) was used for the calculation of volatility. The financial crisis of 2008 had a significant impact on world trade; the tanker shipping market experienced 2 years of shock adjustment and has remained in recession since. Given the cyclical nature of the market, and to increase the reliability of the forecast results, BDTI data from 2010-2016 were used here.

Before applying the GARCH model to the calculations, data processing and data testing were performed. The original BDTI data were logarithmically first-order differenced to reduce heteroscedasticity and to smooth the data. The processed data, designated as R_BDTI, were then subjected to a stationarity test, a correlation test, and an ARCH effect test. The results of the stationarity test are presented in Table 2, indicating that the series is stationary. The correlation of the data was tested by calculating the autocorrelation coefficient and the partial autocorrelation coefficient. The results showed that both were close to 0 at the $5 \%$ level of significance, indicating no autocorrelation ins the R_BDTI data. The ARCH effect test is a necessary step for the subsequent establishment of the GARCH model, which can be established only if there is a significant $\mathrm{ARCH}$ effect in the data series. The test for the $\mathrm{ARCH}$ effect uses the autocorrelation verification of the squared residual series of R_BDTI data. According to the calculation, the autocorrelation coefficient of the squared residuals series was 0.532 , which was greater than 0.5 , corresponding to a $P$-value of less than 0.05 . Therefore, the R_BDTI data series was considered to have a significant ARCH effect.

The parameter cases of the $\operatorname{GARCH}(1,1), \operatorname{GARCH}(1,2)$ and $\operatorname{GARCH}(2,2)$ models were calculated, where the parameters of $\operatorname{GARCH}(2,2)$ all passed the $z$-test at a significance level of $5 \%$ (Table 3 ). The specific values of the parameters of $\operatorname{GARCH}(2,2)$ are presented in Table 3. Dynamic forecasting was performed according to the volatility equation, and the final volatility was calculated as 0.24 . According to Eq. (10), the rising probability $P$ equals 0.57 . Taking the sensitivity factor $\rho$ 
Table 3 Result of $\operatorname{GARCH}(2,2)$ regression

\begin{tabular}{lllll}
\hline Variable & Coefficient & SE & $z$-Statistic & Probability \\
\hline Variance equation & & & & \\
$C$ & $5.40 \times 10^{-5}$ & $6.90 \times 10^{-6}$ & 7.830038 & 0.0000 \\
RESID $(-1)^{2}$ & 0.343449 & 0.032759 & 10.48396 & 0.0000 \\
RESID $(-2)^{2}$ & 0.174669 & 0.056981 & 3.065373 & 0.0022 \\
GARCH(-1) & 0.641423 & 0.102521 & 6.256506 & 0.0000 \\
GARCH(-2) & -0.158794 & 0.048263 & -3.290209 & 0.0010 \\
$R^{2}$ & -0.000013 & Mean dependent variable & $-6.20 \times 10^{-5}$ & \\
Adjusted $R^{2}$ & 0.000559 & SD dependent variable & 0.016896 & -5.488512 \\
SE of regression & 0.016891 & Akaike information criterion & -5.472862 & \\
Sum squared residual & 0.498156 & Schwarz criterion & -5.482726 & \\
Log likelihood & 4796.471 & Hannan-Quinn critter & & \\
Durbin-Watson statistic & 1.004579 & & & \\
\hline
\end{tabular}

as equal to 0.1 , the triangular fuzzy form of the rising factor is $\tilde{u}=\langle 1.24,1.27,1.30\rangle$, and the fuzzy falling factor is $\tilde{d}=\langle 0.77,0.79,0.81\rangle$ according to Eqs. (7) and (8).

\subsection{Fuzzy ROA method}

For the overall analysis of the four tankers, ${ }^{2}$ the planned annual sailing operation is assumed to be 300 days, and the daily rental revenue $\$ 108,336$. Daily operating costs are assumed to be $\$ 64,000$, and annual fixed costs $\$ 5$ million. In the third year, the operator will decide whether to expand the investment by 1.2 times its original size by adding a smaller second-hand vessel, as considered by the company according to prevailing market conditions, at an expansion cost of $\$ 40$ million. The stopping cost (SC) is $\$ 3$ million, the restarting cost (RC) is $\$ 1$ million, and the ships' abandonment cost is $\$ 16$ million in poor market conditions. Figure 4 shows the calculation results for the fuzzy underlying asset and fuzzy option value binomial tree.

Given the operating strategy of the shipping company, it is necessary to judge whether to execute the expansion option in the third year, the details of which are provided in Sect. 3.3. At node $N_{3,0}$, the underlying asset value $S_{3,0}=\$ 221,914$ is greater than the calculated expansion underlying asset $S_{\mathrm{e}}=\mathrm{AOC}+\frac{\mathrm{FC}}{Q}+\frac{F_{\mathrm{e}}}{\alpha Q}$, which equals $\$ 191,777.78$. Therefore, the operator will execute the expansion option at this node. The fuzzy option value $C_{i, j}$ of this node and all its subsequent nodes expands to 1.2 times the original.

The determination of the deferral option is achieved by comparing the magnitude of $S_{i, j}$ with those of $S_{\mathrm{s}}$ and $S_{\mathrm{r}}$. According to Eq. (13), the underlying asset

\footnotetext{
2 The four tankers are considered as 'the investment project'. That is, all assumed figures here, e.g. operating days, revenues and costs, regard the project as a whole and not the individual ships.
} 


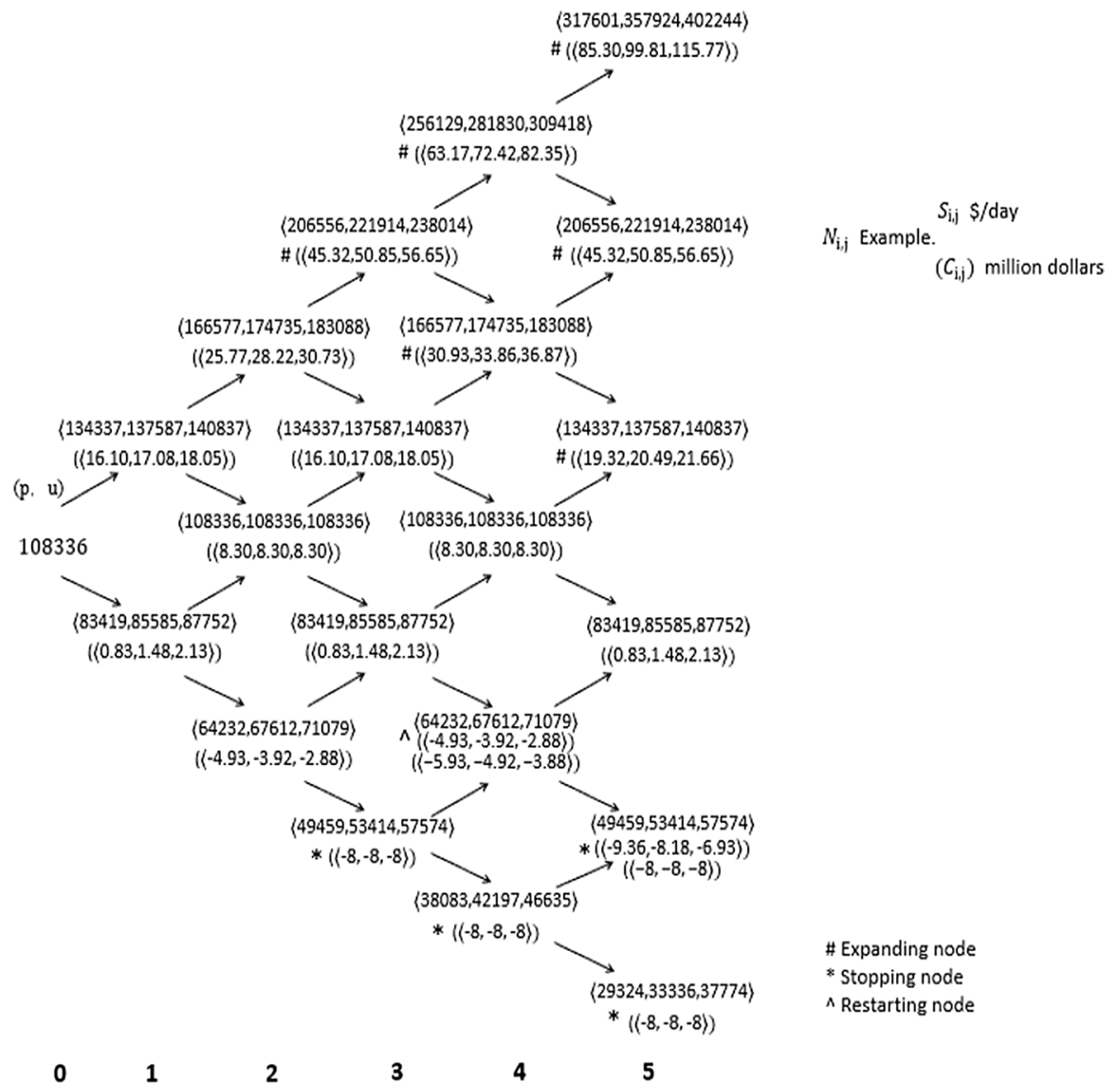

Fig. 4 Fuzzy underlying asset and fuzzy option value binomial tree

value of stopping node $S_{\mathrm{s}}$ equals $\$ 54,000$, while the underlying asset value of restarting node $S_{\mathrm{r}}$ is $\$ 67,333.33$. Node $N_{3,3}$ is the original stopping node, and node $N_{4,3}$ is the original restarting node. In this case, at nodes $N_{3,3}, N_{4,4}$, and $N_{5,5}$, the shipping company ceases to operate the ships with options valued at $\$-8$ million. At the restarting nodes, since the investment behaviour of restarting is based on the previous choice to stop, $C_{i, j}$ can take two values depending on the previous different conditions. For example, at node $N_{4,3}, \$\langle-4.93,-3.92,-2.88\rangle$ million is the fuzzy option value for normal operation, whereas when the previous node is a stopping node, the investor has to pay an additional $\$ 1$ million to restart these ships. At node $N_{5,4}, C_{5,4}$ equals $\$\langle-9.36,-8.18,-6.93\rangle$ million when the previous node is the restarting node, and the option value becomes $\$-8$ million when the preceding node is the stopping node. The abandonment option is considered at the stopping nodes, and according to Eq. (15) the value of each $T_{\mathrm{A}(i, j)}$ is greater than 0 . This investment project does not execute the abandonment option.

The fuzzy total compound option value $\widetilde{C F}_{i}$ for period $i$ is defined by Eq. (16): 


$$
\widetilde{\mathrm{CF}}_{1}=\mathrm{e}^{-r * 1} * \sum_{j=0}^{1} \frac{i !}{j !(i-j) !} P^{i-j}(1-P)^{j} \widetilde{C}_{i, j}=\$\langle 9.09,9.90,10.70\rangle \text { million }
$$

$\widetilde{\mathrm{CF}}_{2}=\$\langle 10.86,11.79,12.73\rangle$ million, $\quad \widetilde{\mathrm{CF}}_{3}=\$\langle 13.50,14.99,16.53\rangle$ million,

$\widetilde{\mathrm{CF}}_{4}=\$\langle 16.27,18.18,20.08\rangle$ million, $\quad \widetilde{\mathrm{CF}}_{5}=\$\langle 18.83,20.70,23.15\rangle$ million,

$$
\widetilde{\mathrm{PV}}=-T_{O}+\sum_{i=1}^{5} \widetilde{\mathrm{CF}_{i}}+\frac{T_{5}}{\mathrm{e}^{r * 5}}=\$\langle-5.49,1.91,9.59\rangle \text { million. }
$$

The fuzzy total present value of the tankers investment project is $\$\langle-5.49,1.91,9.59\rangle$ million. If we take a risk-neutral attitude (that is, $\lambda$ is equal to $0.5)$, the NPV of this investment is $\$ 1.98$ million. This calculation indicates that the investment is recommendable, which was the actual decision of COSCO Marine Energy Transportation Co. Ltd. at the time.

\section{Discussion}

The above case is considered for further analysis using the traditional DCF method. According to this, investment revenue of the ships for each year $\mathrm{CF}_{i}=\left(S_{i}-\mathrm{AOC}\right) * Q-\mathrm{FC}$ equals $\$ 8.3$ million. After the 5-year investment period, the NPV of the ship investment is \$- 10.96 million, discounting the annual revenues and the residual value of the vessels at a risk-free rate of $3 \%$. Accordingly, were the company to invest, it would lose money during the 5-year investment period, which is obviously not recommended. The opposite result was, however, obtained in the previous section, using the fuzzy ROA method. The main reason for this discrepancy is that, when using the NPV method, we assumed that freight rates and revenue would remain the same, regardless of market developments, considering only the investor's initial decision whether to invest or not.

In the fuzzy ROA method, the volatility and uncertainty of the shipping market are simulated by the fuzzy rising factor and the fuzzy falling factor. Furthermore, the flexible adjustments of the operator are abstracted into different kinds of real options. In this case, when the market is high the operator can expand ship operations by adding vessels or increasing the ship utilization rate, while when the market is low the operator can choose to temporarily stop ship operations to limit losses. In short, the fuzzy ROA method takes into account both market fluctuations and the effects of operational flexibility, which is why the two methods obtain conflicting results.

In Sect. 4.2a, $\$\langle-5.49,1.91,9.59\rangle$ million is a triangular fuzzy number calculated using the fuzzy ROA method. The value of $\$-5.49$ million represents the most pessimistic estimation of the investment's value, $\$ 1.91$ million is the most likely NPV, and $\$ 9.59$ million is the most optimistic valuation. Because the investor is assumed 
to be risk-neutral, the expected value of the fuzzy option is calculated by taking $\lambda=0.5$, which yields an expected value of $\$ 1.98$ million. Combined with the cyclical nature of the shipping market, market expectations are on the optimistic side, as the shipping market has experienced a decade of downturn and recession since 2008. If the value of $\lambda$ is changed to 0.85 , the expected value becomes $\$ 4.619$ million. The valuation of the specific option can be adjusted according to the investor's risk preference at the time of the investment decision.

The binomial tree pricing model chosen for pricing real options in ship investments in this study is relatively simple and intuitive, as well as computationally easy, but the corresponding cost is its lack of computational accuracy. According to the assumption of the binomial tree pricing model, the underlying asset has both upward and downward possibilities at each node. In contrast, improved pricing methods, such as the discrete trinomial tree pricing model, increase the likelihood that the underlying asset remains unchanged, but at the cost of a significant increase in computational effort. Additionally, we introduce a sensitivity factor into the process of fuzzifying the rising and falling factors. The sensitivity factor is assigned directly through the investor's possession of information and market forecasts, which are somewhat subjective. Therefore, future research into the fuzzy options method in the field of shipping investment should consider the assignment evaluation system of the sensitivity factor and further optimization of the options pricing method.

\section{Conclusion}

Drawing on previous research on ship investment, this study combines fuzzy mathematics and real options theory to establish a fuzzy real options model of ship investment for value assessment. Compared with traditional discounted cash flow methods (i.e., the NPV method), the fuzzy ROA method used here takes into account not only the uncertainty of shipping market fluctuations but also the flexibility in investor operations. The expansion, contraction, deferral and abandonment options in real options theory are used to mathematically abstract the various types of decision adjustments made by shipping companies in the course of ship operations. The volatility of the shipping market is reflected by the GARCH model based on historical data for dynamic forecasting. The uncertainty of shipping market volatility is further modelled by introducing triangular fuzzy numbers.

The results of using the traditional NPV method and the fuzzy ROA method established in this study are compared and analysed by applying the two methods in the actual investment case of COSCO Marine Energy Transportation Co. Ltd. of 2017. Our results show that, on the basis of the NPV analysis, investment in the tankers was not recommended. In contrast, the expected value of the project, calculated using the fuzzy ROA method, was positive, indicating that the investment was recommended. Compared with the NPV method, the fuzzy ROA method quantifies the operational flexibility of investors in a volatile market environment and transforms market uncertainty into an investment opportunity. From the actual operation of COSCO Marine Energy Transportation Co. Ltd. in recent years, it can be seen that, in 2020, despite the global economy being hit by the COVID-19 pandemic, its 
tankers realized substantive gains. According to the 2020 annual report of COSCO Marine Energy Transportation Co. Ltd., the ship investment it made in 2017, including the four vessels in our case study, all performed well in terms of revenue. This further validates the adaptability and feasibility of the fuzzy ROA method in decision-making in ship investment.

\section{Appendix}

A fuzzy set is a set used to express the concept of fuzziness. This method regards the research object and the fuzzy concepts that reflect it as a certain fuzzy set, and establishes an appropriate fuzzy membership function, analysing the fuzzy object through the relevant operations and transformations of the fuzzy set. The meaning of a fuzzy set is that an element $x$ has "a certain probability" of belonging to set $\tilde{A}$, or "to some extent" to set $\tilde{A}$. In contrast to traditional mathematical sets, where the degree of affiliation of elements is either 0 or 1 , i.e. they either belong or not, a degree of uncertainty is introduced in fuzzy sets. The fuzzy membership function: $u_{\tilde{A}}: U \rightarrow[0,1]$ specifies a value $u_{\tilde{A}}(x) \in[0,1]$ corresponding to $x$. The value of $u_{\tilde{A}}(x)$ at element $x$ reflects the degree to which element $x$ belongs to $\tilde{A}$. Let a fuzzy set $\tilde{A}$ on a domain of discourse $U$, if the fuzzy membership function $u_{\tilde{A}}: U \rightarrow[0,1]$ can be expressed as

$$
u_{\tilde{A}}(x)= \begin{cases}\frac{x-a}{b-a}, & a<x \leq b, \\ \frac{x-c}{b-c}, & b<x \leq c, \\ 0, & x<a \text { or } x>c,\end{cases}
$$

then $\tilde{A}$ is a triangular fuzzy set, or it can be called a triangular fuzzy number. Triangular fuzzy numbers can be regarded as special trapezoidal fuzzy numbers that also satisfy the relevant algorithm of trapezoidal fuzzy numbers.

Acknowledgements We would like to express our great appreciation to MEL referees and editors.

\section{References}

Acciaro, M. 2014. Real option analysis for environmental compliance: LNG and emission control areas. Transportation Research Part D: Transport and Environment 28: 41-50.

Allenotor, D., and R.K. Thulasiram. 2011. Grid resources valuation with fuzzy real option. International Journal of High Performance Computing and Networking. https://doi.org/10.1504/IJHPCN.2011.038704.

Arasteh, A., and A. Aliahmadi. 2013. A proposed real options method for assessing investments. The International Journal of Advanced Manufacturing Technology 70 (5-8): 1377-1393.

Bendall, H.B. 1979. Coal-fixed turbines versus diesel: An Australian context. Maritime Policy and Management 6 (3): 209-215.

Bendall, H.B., and A.F. Stent. 2003. Investment strategies in market uncertainty. Maritime Policy and Management 30 (4): 293-303.

Bendall, H.B., and A.F. Stent. 2007. Maritime investment strategies with a portfolio of real options. Maritime Policy and Management 34 (5): 441-452. 
Black, F., and M. Scholes. 1973. The pricing of options and corporate liabilities. The Journal of Political Economy 81 (3): 637-654.

Bollerslev, T. 1986. Generalized autoregressive conditional heteroskedasticity. Journal of Econometrics 31 (3): 307-327.

Carlsson, C., and R. Fullér. 2003. A fuzzy approach to real option valuation. Fuzzy Sets and Systems 139 (2): 297-312.

Chrysafis, K.A., and B.K. Papadopoulos. 2007. On theoretical pricing of options with fuzzy estimators. Journal of Computational and Applied Mathematics 223 (2): 553-566.

Cox, J.C., S.A. Ross, and M. Rubinstein. 1979. Option pricing: A simplified approach. Journal of Financial Economics 7 (3): 229-263.

Dikos, G. 2008. Real options econometrics for aggregate tanker investment decisions. International Journal of Ocean Systems Management 1 (1): 31-44.

Evans, J.J. 1984. Some practical aspects of investment appraisal in shipping. Maritime Policy and Management 11 (3): 197-222.

Hye, Y.G., and H. Eunnyeong. 2009. A valuation for gas hydrate R\&D project using fuzzy real options model. Environmental and Resource Economics Review 18 (2): 217-239.

Kavussanos, M.G. 1996. Comparisons of volatility in the dry-cargo ship sector: Spot versus time charters, and smaller versus larger vessels. Journal of Transport Economics and Policy 30 (1): 67-82.

Kavussanos, M.G. 1997. The dynamics of time-varying volatilities in different size second-hand ship prices of the dry-cargo sector. Applied Economics 29 (4): 433-443.

Kyriakou, I., et al. 2018. Income uncertainty and the decision to invest in bulk shipping. European Financial Management 24 (3): 387-417.

Muzzioli, S., and H. Reynaerts. 2007. American option pricing with imprecise risk-neutral probabilities. International Journal of Approximate Reasoning 49 (1): 140-147.

Myers, S.C. 1977. Determinants of corporate borrowing. Journal of Financial Economics 5 (2): $147-175$.

Slade, M.E. 2001. Valuing managerial flexibility: An application of real-option theory to mining investments. Journal of Environmental Economics and Management 41 (2): 193-233.

Yin, J., Y. Wu, and L. Lu. 2018. Assessment of investment decision in the dry bulk shipping market based on real options thinking and the shipping cycle perspective. Maritime Policy and Management 46 (3): 330-343.

Yoshida, Y. 2003. The valuation of European options in uncertain environment. European Journal of Operational Research 145 (1): 221-229.

Zadeh, L.A. 1965. Electrical engineering at the crossroads. IEEE Transactions on Education 8 (2): 30-33.

Publisher's Note Springer Nature remains neutral with regard to jurisdictional claims in published maps and institutional affiliations. 